\title{
TRES POETAS MARRANOS ${ }^{1}$
}

Si recordamos que el apogeo de la edad de oro de la literatura española, a partir de los últimos años del siglo XVII, coincidió con un resurgimiento de los conversos en el seno de la sociedad española, no debería sorprendernos que los conversos judaizantes - los marranos- hayan participado en el esplendor literario de este período. En el año de 1580 España y Portugal se unieron bajo una sola monarquía; al mismo tiempo se reforzó el judaismo entre los conversos españoles por influencia de los conocimientos superiores de los descendientes portugueses de la Conversión General de 1497. En el mismo período, Amsterdam surgió como un centro judío, y, junto con las comunidades ya establecidas de Livorno y Venecia, servían de apoyo moral, religioso y cultural, empleando medios tales como la reimpresión de los libros de oraciones y las Biblias en idioma vernáculo publicados por primera vez en Ferrara en el decenio de 1550. El movimiento de hombres e ideas aumentó también entre España y las ciudades francesas de Bayona, Burdeos, Nantes y Rouen, donde había grandes comunidades de conversos en cuyo seno florecía el criptojudaísmo. Todos estos factores contribuyeron a dar un nuevo impulso al judaismo de aquellos que, en todos los aspectos, salvo el religioso, eran culturalmente españoles. Sus raíces literarias estaban en la herencia poética de Garcilaso, Herrera y fray Luis de León, en la tradición dramática de Lope de Vega y Calderón de la Barca y en las epopeyas nacionales de Ercilla y otros que seguían los modelos de la épica italiana ${ }^{2}$. Así pues, era natural que la expresión literaria del individuo producto de esos antecedentes reflejara los patrones y los estilos artísticos del Siglo de Oro español, como lo hacían los escritos de los cristianos viejos o nuevos. El verso majestuosos de João Pinto Delgado tiene resonancias de los grandes poetas de la época de Garcilaso a Góngora, pero también de las muy cristianas alegorías espirituales de fray Luis de Granada; Antonio Enríquez Gómez escribió obras teatrales, que se han atribuido a Lope y Calderón, y un poema épico Sansón Nazareno (Rouen,

\footnotetext{
Este artículo está basado en mi antología Marrano poets of the seventeenth century, que se publicó en la Littman Library of Jewish Civilization East Brunswick, New Jersey, 1982. Todas las citas poéticas están tomadas de esa edición, a menos que se especifique lo contrario.

${ }^{2}$ Las relaciones con la tradición hebrea del período árabe habían sido completamente destruidas, en cualquier grado de significación.
} 
1656), que está en la tradición directa de Tasso y sus imitadores españoles. Muchos poetas conversos adoptaron la misma combinación de la forma épica con temas del Antiguo Testamento o de la Apócrifa. ${ }^{3}$

Lo interesante para nosotros no es simplemente que tenemos una colección de textos literarios de un grupo minoritario especial digna de tomarse en cuenta, sino que esos escritores marranos explotaron el recurso cultural que les era familiar para expresar su reacción frente a la situación de inseguridad, frecuentemente dramática, en la que se encontraban. En las obras de los tres poetas más significativos, João Pinto Delgado, Antonio Enríquez Gómez y Miguel de Barrios, que son el tema de este ensayo, vemos en realidad tres caminos hacia el judaismo diferentes, pero típicos a su manera. Pinto Delgado ${ }^{4}$ fue criado en el judaismo clandestino desde temprana edad y pronto, después de haber completado su educación literaria en Lisboa, salió de Portugal hacia Francia, y en especial Rouen, donde se convirtió en un miembro importante de su comunidad criptojudía relativamente ortodoxa. El profundo arraigo de su cultura judaica le favoreció cuando dejó la clandestinidad y llegó el momento de irse a Amsterdam. También Barrios ${ }^{5}$ debe haber tenido una buena formación criptojudía, pero tardó un poco más en establecerse permanentemente en Amsterdam (en una época dividió su tiempo entre Bruselas, que estaba bajo el dominio español, y la comunidad judía de la ciudad holandesa) y al final se desvió por caminos mesiánicos de inspiración cristiana. Era un ser social, antiguo oficial del ejército, acostumbrado a moverse en círculos elevados o sofisticados, poseedor de un vivo ingenio que fluye en sus versos y le sirve como

3 Por ejemplo, Estrella Lusitano (seudónimo), La Machabea, León 1604; Jacobo Uziel, David, Venecia, 1624; Miguel de Silveira, El Macabeo, Nápoles, 1638.

4 Joáo Pinto Delgado (mediados del decenio de 1580-1653) pasó los primeros años de su vida en el Algarve y Lisboa. En 1624 se reunió con sus padres expatriados en Rouen. Implicado en el conflicto de 1633 entre conversos judaizantes y conversos cristianos, huyó a París, luego a Antwerp y Amsterdam, donde adoptó el nombre de Moseh. Fue elegido como uno de los parnasin (gobernadores) del Seminario de Talmud Torah, Amsterdam, en 1633 y 1640. Sus obras, todas en español. son: Poema de la Reyna Ester, Lamentaciones del Propheta Ieremias, Historia de Rut, y Varias Poesías, Rouen, 1627. Escribió poemas autobiográficos que se encuentran en el ms. 48 D 39 "Diálogos contra a cristiandade" (título dado por un bibliógrafo posterior), en la biblioteca del Portuguees Israelitisch Seminarium «Ets Haim», Amsterdam; véase I.S. REVAH, "Autobiographie d'un marrane, édition partielle d'un manuscrit de Joáo (Moseh) Pinto Delgado", REJ, 119 (1961), 89-130.

${ }^{5}$ Miguel de Barrios (1635-1701), nacido en Montilla (Córdoba), huyó a Nápoles en 1650; se casó y viajó a Tobago, donde murió su mujer. Fue capitán de caballería en Bruselas y, simultáneamente, miembro de la comunidad judía de Amsterdam. Hacia 1672 volvió a casar, se estableció definitivamente en Amsterdam, y adoptó el nombre de Daniel Levi. Obras principales: Flor de Apolo, Bruselas, 1665; Coro de las Musas, Bruselas, 1672; Libre Albedrio, Bruselas, 1680; Triumpho del Govierno Popular y de la Antigüedad Holandesa, Amsterdam, 1683; Estrella de Jacob sobre flores de lis, Amsterdam, 1686; Imperio de Dios en la Harmonía del Mundo [Amsterdam, 1700?]. 
cronista de la vida de la comunidad judía, al tiempo que aparece con frecuencia un profundo sentimiento religioso.

Enriquez Gómez se inclinaba hacia la política y el comerció ${ }^{6}$ le atraía la vida mundana y formaba parte de ella, pero podía hacerle burla en sus versos. El fondo criptojudío estaba menos presente que en los demás, y fue necesaria una crisis en su vida, a la edad de cincuenta años, para que se aclarara la cuestión de su judaismo (cuando trataba de decidirse entre continuar hacia Amsterdam y volver a España: escogió el segundo camino). Aun entonces, su judaismo fue algo libresco, sin las ventajas prácticas que tenía la sociedad abiertamente judía de Amsterdam. En realidad, puede decirse que siguió siendo un marrano toda su vida.

Claro está que esos caminos diferentes y las experiencias que trajeron consigo afectaron el contenido y el tono de la obra de cada uno de los poetas. El hecho de vivir constantemente con el temor de la Inquisición dejó su marca en las imágenes y las alusiones autobiográficas en las obras de los tres poetas, aunque ninguno sufrió las prisiones y torturas de la Inquisición, como ocurrió con David Abenatar Melo, que intercala en sus "traducciones" en verso de los Salmos relatos de su experiencia personal ${ }^{7}$. Por otra parte, un rasgo frecuente en el verso de Enríquez Gómez es la siniestra figura del malsín, el delator, cuyas denuncias (verdaderas o falsas) podían atraer las miradas de la Inquisición hacia algún individuo y arrastrarlo a la cadena de persecuciones en la que hasta los testigos serían objeto de una investigación metódica. Para João Pinto Delgado, en sus poemas autobiográficos inéditos, las mismas puertas de Lisboa simbolizan la presencia de la Inquisición y sus torturas ${ }^{8}$. Al mismo tiempo, la incertidumbre de la vida del converso en tales condiciones se encuentra simbolizada en la figura del "peregrino", no el peregrino del habla común, sino el "errante", cuyo destino es ser

\footnotetext{
6 Antonio Enríquez Gómez (Cuenca, ca. 1600-1663), de familia judaizante; casado en 1618; para 1624 establecido en un comercio en Madrid; en la misma época empieza su carrera como poeta y dramaturgo; frecuenta el círculo de Lope de Vega; sale al exilio hacia Francia (Burdeos, Rouen), en 1635; involucrado en la misión portuguesa en Francia, apoya la independencia de Portugal; vuelve a España en 1649; quemado en efigie en Sevilla, 1660; arrestado por la Inquisición en 1661, muere en espeta de la sentencia el 18 de marzo de 1663 ; reconciliación póstuma con la Iglesia en 1665 . Obras principales: Academias morales de las Musas, Pedro de la Court, Bordeaux, 1642; La culpa del primer peregrino, Laurent Maurry, Rouen, 1644; El siglo pitagórico, Maurry, Rouen, 1644; La Torre de Babilonia, Maurry, Rouen, 1648; Sanzón Nazareno, Maurry, Rouen, 1656; "Romance al diuin Martir Judá Creyente", ms. opp. add. $4^{\circ}$ 150, Bodleian Library, Oxtord, véase mi edición publicada en “Antonio Enríquez Gómez" «Romance al divín mártir, Judá Creyente». Edited text with introduction", Journal of Jewish Studies, 26 (1975), 113-131.

${ }^{7}$ La versión del Salmo 30 de Abenatar Melo es el ejemplo sobresaliente; contiene los versos: "En el infierno metido / de la inquisición dura / entre fieros leones de albedrío / de allí me has redimido".

8 "Aquí está la infame puerta, / la del olivo y la espada, / para salir tan cerrada, / y para entrar tan abierta" ("Autobiographical Poems" 1, 11.1-4).
} 
exiliado en su patria, y que con frecuencia se ve obligado a buscar el exilio en el extranjero. El título mismo del poema de Enríquez Gómez sobre el tema de Adán, La culpa del primero peregrino, es un testimonio de esto (Adán es considerado como el exiliado arquetípico), al mismo tiempo que señala otro motivo importante, el del pecado original. Aunque es un concepto profundamente cristiano, se conserva como una metáfora de la condición del converso, provocada por el estigma de su nacimiento. Se encuentran ejemplos de esto en los primeros escritos de Pinto Delgado, de Enríquez Gómez y, en menor medida, en los de Barrios.

La aceptación de una doctrina como la del pecado original, aun en un nivel metafísico, nos lleva a notar la influencia imborrable del ambiente cristiano en los tres poetas. Esto viene del concepto de la salvación a partir de la "creencia en" la Ley (comparable a la creencia en Cristo, que da acceso a la redención), y de una preocupación en el autosacrificio como prueba última del compromiso religioso $^{9}$, hasta las repetidas sugerencias de una comparación subyacente entre judaismo y cristianismo, que pueden aparecer incluso en los poemas mas "judíos" de Miguel de Barrios. Se encuentra un ejemplo de esto último en su "Alabanza jocosa a la Ley" que, aunque está repleta de alusiones a la sinagoga, describe la Ley como algo que tiene el poder de dar la muerte a aquellos que siguen "la Ley de Espada", que es una referencia a la cristiandad inquisitorial. También siente la necesidad de afirmar que la Ley judaica lleva ropajes imperecederos "y no de tela pasada", en referencia a la opinión eclesiástica de que el judaismo es una religión del pasado. Sólo Pinto Delgado, en sus poemas de 1622, parece haberse liberado de los residuos de influencia cristiana tanto en su teología como en la confianza que tiene en su judaismo, pero rememora su pasado de marrano, expresándolo con el tono de los profetas del Antiguo Testamento, en el tema de Israel responsable por sus penas. Además, los primeros poemas autobiográficos muestran claramente que los orígenes del tema vienen de su situación de converso. Exploran los restos de culpa que siente el poeta por su conversión al cristianismo y lo inadecuado de su obediencia a la ley judaica en tales condiciones, tema éste que también aparece en los otros dos poetas ${ }^{10}$. Por último, la esperanza de redención mesiánica, que se encuentra en los tres escritores, es un tema que quizás surge naturalmente de la experiencia de los conversos y que aumenta en ímpetu e importancia por medio de la influencia del cristianismo. Miguel de Barrios se convirtió en seguidor de Sabbatai Zevi, pero la más extraña y conmovedora explosión de fervor mesiánico es la que se encuentra en el

\footnotetext{
${ }^{9}$ El tema del martirio es intenso en la poesía de Enríquez Gómez, especialmente en Sansón Nazareno y "Romance al divín mártir, Judá Creyente".

${ }^{10}$ Véanse el Sansón Nazareno de Enríquez Gómez (canto XIV) y la "Real consideración del hombre" de Barrios, de los que se habla más adelante.
} 
"Romance al divín mártir" de Enríquez Gómez, donde se combina con el tema del martirio.

El pasado hispanocristiano se conserva en esos poetas marranos e influye en las imágenes, los temas y las alusiones, la teología y, como ya hemos dicho, en su lenguaje poético. Sin embargo, podemos ver al mismo tiempo los arduos esfuerzos de cada uno de los poetas por inyectar en su verso una dimensión judía, por medio de la cual se irradie su compromiso con el judaismo. Todos recurren a la Biblia como manual de experiencia y utilizan no sólo sus temas, sino también su estilo y su lenguaje. El tono del lenguaje de jeremías está vividamente presente en las palabras de Pinto Delgado; el de Kohelet y Ben Sira en las de Enríquez Gómez. Barrios está menos orientado hacia la Biblia, salvo por alusiones y temas que formula en un estilo totalmente barroco; pero se inspira a menudo en el libro de oraciones en lengua vernácula y parafrasea su lenguaje en vez del de la Biblia. Además, los tres poetas buscan más allá de la Biblia, en la tradición oral contenida en las deliberaciones rabínicas del Talmud, y entretejen el material que toman prestado, por lo general de fuentes indirectas, en la trama de su verso para darle una mayor riqueza cultural judía. Este enriquecimiento cultural, más lo que sabemos, por medio de sus biografías, de su compromiso religioso, es lo que los separa de las tendencias religiosas más vagas de otros escritores de origen conversoll ${ }^{11}$ Al mismo tiempo, les confiere un lugar especial dentro de la literatura española, como poetas que se incriben dentro de su tradición, aunque se separen de ella en lo religioso.

Hasta ahora hemos considerado a nuestros tres poetas desde el punto de vista general y de las características que tienen en común; sería apropiado ilustrar en este momento sus cualidades individuales y transmitir el sabor de sus obras. Joáo Pinto Delgado es indudablemente el más importante de los tres, un poeta muy valioso desde cualquier punto de vista. Se ubica en los comienzos del siglo XVI y muestra fácilmente la influencia de Garcilaso y Herrera, pero también la de sus contemporáneos, Góngora y Luis de León (cuyas obras manuscritas circulaban durante su estancia en Lisboa). Su verso es claro, elegante y de buen gusto, pero al mismo tiempo está imbuido de conocimientos judaicos y de un profundo sentido de religiosidad judía. En realidad, esta combinación de un estilo contemporáneo lleno de destreza con una cultura judía y un sentimiento religioso de gran profundidad constituye la esencia de su obra. Esto se ve con la mayor claridad en el hecho de que la mayor parte de su poesía ${ }^{12}$ se ocupa de temas tomados directamente de la Biblia y de

1 Por ejemplo, Miguel de Silveira en El macabeo, cuyo tema puede ser, en términos generales, el de la liberación, pero que no contiene ningún indicio de sentimientos judaizantes.

12 Todos los poemas de la colección de 1627, Poema de la Reyna Ester, etc., o bien cuentan historias bíblicas o bien las usan como punto de partida. 
que, casi siempre, el poema es una reelaboración del texto bíblico en la lengua de los Siglos de Oro. Aunque conserva todo el contenido del original, Pinto añade sus propios adornos poéticos e introduce comentarios frecuentemente derivados de fuentes talmúdicas, en una forma que, para su época, nunca deja de ser pertinente ni apropiada.

Se puede ver un ejemplo de su método en el Poema de la Reyna Ester (primer fragmento: «El sueño y las lástimas de Mardochay»), donde Mardocai se lamenta por el decreto de Hamán contra los judíos. El pasaje toma como punto de partida el texto de Esther, 4.1, pero está precedido por un sueño de dos dragones en lucha (Mardocai y Hamán) que son separados por un torrente (Esther), cuya intervención salva al "breve escuadrón de aflicta gente" (los judíos amenazados). El sueño está presente en la Esther apócrifa, pero en realidad Pinto se inspira en una versión que se encuentra en el Yalkut, el comentario de R. Simeon Qara Hadarshan al Libro de Esther, que pinto conocía por la traducción latina de Louis-Henri d'Aquin ${ }^{13}$. El pasaje está precedido por un comentario derivado de Rashi, en el sentido de que la amenaza a los judíos es un castigo por la idolatría cometida en tiempos de Nabucodonosor:

En sueño alcanza Mardochay que el castigo justo, contra Israel, del cielo se prepara, si reinando Nabuc con culto injusto atrevido sus dioses adorara, y de Asuero fue, por su delicia, agradable la mesa en su inmundicia.

Se puede observar que la alusión está fundida en el lenguaje poético por medio del estilo oblicuo y la yuxtaposición de las referencias a Nabuc y Asuero en forma tal, que se hace resaltar la relación pasadopresente que constituye el mensaje de la fuente. El enfoque es totalmente poético, no de alabanza propia.

En el lamento de Mardocai que sigue al sueño, el poeta elabora el tema de la responsabilidad que tiene Israel por sus apuros presentes, sólo que esta vez lo que se resalta es la conexión con las causas del exilio en Babilonia. Tanto la tragedia principal como tragedia en potencia se atribuye al hecho de que Israel no ha sabido respetar la ley. Así empieza Mardocai su lamento:

13 Véase A.D.H. FISHLOCK, "The rabbinic material in the «Ester» of Pinto Delgado", Journal of Jewish Studies, 2(1950-51), 37-50. Para un estudio completo de éste y otros aspectos de la poesía de Pinto Delgado, véase la tesis de A. D. H. FISHLOCK, The poems of João Pinto Delgado, Univ. of London, 1952. 


\begin{abstract}
iAh, de Jacob los hijos castigados, que, en los tormentos del antiguo daño, en vuestro mal envueltos los pecados, la cerviz humilláis a jugo extraño, mirad agora vueltas las cadenas en vuestro fin y el fin de vuestras penas!

Pues de Sión el alto bien perdistes, preparad al cuchillo vuestros cuellos: será la pena a tanto error, si vistes el instrumento de soberbia en ellos; que quien su ley entre su gloria olvida, poca es la paga, si lo fue la vida.
\end{abstract}

Sin embargo, esta justıtıcación moral de la amenaza divina en el momento presente no disminuye la intensa sensación de simpatía por los sufrimientos de los judíos. Por el contrario, evoca conmovedoramente sus sufrimientos y su angustia, y ruega a Dios que perdone a los que han sobrevivido como resto de la destrucción de Jerusalén. Al hacerlo, se refiere a los ritos del Templo y en particular a la proclamación, por el Sumo Sacerdote, del Tetragrammaton, "el inefable Nombre", en el santuario interior en el Día del Perdón, y pregunta: ¿Quién no hubiera sacrificado su vida para defenderlo del enemigo? La alusión específica al Sancta Santorum y a un rito que ya no se practicaba en el exilio subraya en forma por demás emotiva el tono y el tema de este pasaje, y es un ejemplo más de la forma en que Pinto Delgado realza su verso con materiales que no vienen de las fuentes bíblicas inmediatas.

Se podría seguir ilustrando la riqueza del verso de Pinto Delgado con el Poema de la Reyna Ester, al igual que con otros poemas de la colección de 1627. Sin embargo, el ejemplo supremo se encuentra en las Lamentaciones del profeta Jeremías, que se considera con razón como la obra maestra de este poeta. Este poema, basado en el Libro de las Lamentaciones, lo glosa verso por verso, incluyendo el texto de la Biblia de Ferrara junto con la paráfrasis del poeta, y está repleto de alusiones bíblicas y referencias talmúdicas tomadas de los $\mathrm{Co}$ mentarios de Cornelius a Lapide, todo ello entretejido para dar un ejemplo consumado del arte del poeta. La sutileza se combina con la sencillez de expresión, los recursos retóricos complejos con una emoción sincera, y el tono va de lo patético a lo austeramente moralizador al modo de los profetas del Antiguo Testamento. La situación básica de la caída de Jerusalén se convierte en un ensayo poético sobre el tema, que tanto trata el poeta, de las tribulaciones de Israel como castigo divino, combinado con la afirmación de la fe en que Dios concederá la redención final. A partir de la paráfrasis inicial de las bien conocidas palabras de Lamentaciones 1.1, "Có- 
mo está sentada sola la ciudad populosa!", Pinto se concentra en el tema moral, y no en las pruebas físicas de abandono ${ }^{14}$.

¿Cuál desventura, o ciudad, ha vuelto en tan triste estado tu grandeza y majestad y aquel palacio sagrado en estrago y soledad?

¿Quién a mirarte se inclina y a tus muros derrocados por la justicia divina que no vea en tus pecados la causa de tu ruina?

¿Quién te podrá contemplar, viento tu gloria perdida, que no desee que un mar de llanto sea su vida, para poderte llorar?

Cuál pecado pudo tanto que no te conozco agora? Mas, advirtiendo, me espanto, que tú fuiste pecadora y quien te ha juzgado santo.

$$
\text { (1.1, 1-20) }
$$

Las ruinas mismas hablan de juicio divino y no de desventura ocasional al observador informado, al poeta que vaga por las calles abandonadas en busca de alguien que explique las circunstancias, a la manera de Jeremías (véase Jeremías 5.1).

Al avanzar el poema, los motivos introducidos en el pasaje anterior van tomando cuerpo y se unen a una compleja serie de referencias bíblicas. La ruina de Sión, que no sólo representa su dolor y su destrucción física, sino también su pecado moral y el castigo divino, se traduce en imágenes de Sión como la mujer caída de Ezequiel (a lo cual apunta la "pecadora" de 1.19 supra), la mujer menstruante de Isaías, la vid que recoge el Dios del Juicio (Isaías, 5 y Ezequiel, 15), y pasa de ahí al huerto abandonado cuyos frutos ha malgastado Israel. Este último motivo se desarrolla ampliamente en la glosa a Lamentaciones, 2.6 que es, por lo demás, un estupendo ejemplo del estilo gongorino de Pinto, donde cada fruto se desarrolla con miras a su simbolismo; por ejemplo:

La granada abre el coral que por mostrarse revienta y en su corona real la fe de un rey representa en su vasallo leal.

(II. 6, 26-30)

14 Compárese la versión de Quevedo, "Las lágrimas de Hieremías castellanas" en la ed. de J.M. Blecua y E.M. Wilson, Madrid, 1953. (RFE, anejo 55). 
También el fuego es un símbolo frecuente, la evocación más profunda del poder divino, y Pinto le dedica toda una secuencia en la Lamentación 1.13:

El fuego de su venganza mandó del cielo el Señor contra mi necia esperanza, cual rayo que en su furor sólo en la muerte descansa.

En lo que sigue, los incendios que destruyeron las torres de Jerusalén se relacionan con los que destruyeron la Torre de Babel15: "la lengua de su ceniza" dice volúmenes enteros a propósito de su insensatez. El fuego del juicio divino se muestra como respuesta al fuego de su insensatez. El fuego del juicio divino se muestra como respuesta al fuego menguante del celo de Israel: "Con justo furor el cielo / el material alimenta / por dar venganza a su celo". En otras estrofas se hace referencia a los distintos incidentes bíblicos en los que predomina el fuego: Moisés y la zarza ardiente, los tres jóvenes en el horno de fuego de Daniel 3, la competencia de Elias con los profetas de Ba'al y la plegaria de Salomón para que el fuego consuma el sacrificio del Templo (II Crónicas 6-7). Esta clase de explotación múltiple de referencias asociadas no sólo muestra extensos conocimientos bíblicos, sino que tiene un espíritu muy conceptis$\operatorname{ta}^{16}$.

Por último, antes de dejar a Pinto Delgado, es importante subrayar el propósito moral de este esfuerzo poético: el tema de que Israel es responsable de sus congojas no sólo relaciona al poeta con la tradición profética de Israel - un elemento esencialmente judaico de continuidad histórica - sino también con su propio pasado de marrano. Así como en Ester y en el Libro de las lamentaciones se habla de las consecuencias de no respetar los mandamientos divinos y del juicio inevitable de Dios, los Poemas autobiográficos ${ }^{17}$ escritos en Portugal hablan de lo inadecuado de su obediencia a las leyes judaicas en el pasado (lo cual es una "culpa" común de los marranos) y del concepto de la Inquisición como instrumento de Dios para hacer que los conversos vuelvan al judaismo. En el primero de

15 La idea proviene del Targum, a través de Cornelius a Lapide, Commentaria in quatuor prophetos maiores, Paris, 1622, col. 519.

${ }^{16}$ Estos ejemplos sólo son algunos de los motivos bíblicos que usa el poeta; para un estudio completo, véase la tesis de Fishlock (nota 13, supra) y, del mismo autor, "The Lamentaciones of João Pinto Delgado", Atlante, 3(1955), 47-61.

17 Estos poemas forman parte de un relato en prosa y verso de su "viaje al judaismo" que se encuentra en el ms. Etz Haim, los llamados "Diálogos contra a cristiandade"; véase también I.S. Révah, art. cit. supra, nota 4. 
estos poemas, «A la salida de Lisboa» ${ }^{18}$, Pinto censura duramente a la Inquisición por su salvajismo y añade la advertencia siguiente:

Y aunque nace tu alegría

viendo a tantos perecer,

si a muchos los hiciste ver

también has de ver tu día.

Si nuestro pecado obliga

a sufrir tanto rigor,

considera que el Señor

si disimula, castiga.

Este doble mensaje se desarrolla luego en el resto del poema, con una advertencia a "Esaú" del juicio que vendrá y una exhortación a "Jacob" para que obedezca los preceptos divinos.

El segundo poema celebra la partida de un amigo hacia climas más seguros, al tiempo que introduce el tema de su propio sentimiento de culpa por no seguir el mismo camino hacia una vida judía plena en Amsterdam. Aunque afirma que "me detiene aquí / tan forzoso inconveniente", está plenamente consciente de la hipocresía de acudir a Dios en un aprieto cuando debería tomar medidas para abandonar las "inmundicias" en las que se encuentra:

O terrible inclinación del hombre que no procura la senda que es más segura y sigue a la salvación.

No más engaño que clama por rigor del infierno: "iAcude, o Señor eterno, y ampara al pobre que llama!"

(11. 129-36)

El tercer poema de la secuencia, "En alabanza del señor", expresa la angustia del poeta en su dilema moral, consciente de que quedarse es una insensatez, pero, incapaz de marcharse, consciente de su necesidad de ayuda divina y también de su propia indignidad. Este poema es la única incursión conocida de Pinto en la terza rima y es una obra conmovedora, de una grandeza igual a la de las Lamentaciones. La falta de espacio nos impide hacerle justicia citándola en su totalidad, pero el fragmento siguiente puede dar alguna idea de su valor:

Del tiempo mío hice, mi Dios alarde, y vi en los bosques, sin hallar salida

\footnotetext{
${ }^{18}$ Los títulos de los poemas son míos, aunque se derivan del texto en prosa que los acompaña.
} 
temprano el mal, el desengaño tarde.

Colgó de un hilo breve la homicida espada de la muerte, y con la muerte, la pena eterna de la inmortal vida.

Contra el contrario, con tu mano fuerte vibraste el dardo, y si quedó vencido, su sinrazón y tu razón lo advierte.

De un monte a otro anduve tan perdido que de la propia diestra me olvida, que es memoria del mal, del bien olvido.

A vanas apariencias me humillaba, árboles que criara el agua, y viento, de mi ignorancia siendo el alma esclava.

Pero si el cielo llama el pensamiento de lo interior del corazón indicio, alta Deidad en mis objetos siento...

Hay aquí reminiscencias de los Salmos de David fundidas en una expresión de sensibilidad lírica como la que se encuentra en las Eglogas de Garcilaso.

El segundo de nuestros poetas, fue el menos abiertamente judío de los tres. Pasó la mayor parte de su vida en España, con unos quince años en exilio en Francia, desde donde volvió a su tierra natal por razones que todavía no han sido completamente explicadas pero que quizás tengan que ver con su españolismo y su deseo de vivir en España en calidad de converso, o incluso de judaizante ${ }^{19}$. Así, nunca llegó a una soceidad donde sus creencias religiosas pudieran expresarse abiertamente y sólo el manuscrito del "Romance al divín mártir" nos puede indicar sus verdaderos sentimientos. Su religión se revela especialmente en las insinuaciones veladas y en los matices enfáticos de sus obras. Como Pinto Delgado, recurre para sus temas a la Biblia: La culpa del primer peregrino sobre el tema de Adán, Sansón Nazareno, sonetos sobre Adán, Enoc y Noé y, en las Academias morales, varios poemas más largos sobre temas tales como el rapto de Dina y la creación del mundo ${ }^{20}$. El recurso repetido al tema de Adán ya ha sido explicado como preocupación de los conversos con el estigma del nacimiento, pero también alude frecuentemente a

\footnotetext{
19 Vale la pena tomar en cuenta que las principales obras en prosa, además de muchos de los poemas y de las obras teatrales, se ocupan de la causa de la independencia portuguesa o del lugar de los cristianos nuevos en la sociedad española, es decir, de los derechos de las "naciones dentro de las naciones" (véase Triumpho Lusitano, París y Lisboa, 1641, y Política angélica, Rouen, 1647, respectivamente). Su regreso a España también puede haber tenido una dimensión mesiánica, ya que la llegada del Mesías, que creía inminente en 1648, traería la seguridad para los judaizantes españoles.

${ }^{20}$ También escribió varias obras teatrales sobre temas bíblicos, como por ejemplo, $\mathrm{La}$ prudente Abigail (en Academias morales) y Las soberbias de Nembrot.
} 
la Torre de Babel (véase La Torre de Babilonia, 1648) como representante de la locura del mundo en general y de la iniquidad de la Inquisición en particular.

Enríquez Gómez usa el libro de Job y el Eclesiastés (junto con otras fuentes, el libro de la Sabiduría, el Eclesiástico y Proverbios) en una forma que quizá sea más significativa. En primer lugar, los aprovecha extensamente desde el punto de vista del "carácter", es decir, de la actitud que representan - Job como el Hombre angustiado que se enfrenta a la dureza de la justicia divina, Salomón como el que, cansado de los placeres mundanos, reconoce la insensatez humana. En segundo lugar, se usan para sugerir que la solución de los problemas humanos está en la búsqueda de la justicia social en esta vida, en vez de la esperanza de redención en la otra. Esto se puede interpretar ya sea como un enfoque judío en sí mismo o como uná búsqueda de soluciones judaístas ${ }^{21}$. Hay muchos poemas o pasajes basados en una de estas dos fuentes (o las dos juntas) en Academias morales, El siglo pitagórico y La culpa del primer peregrino. Citaremos a manera de ejemplo un pasaje de este último poema:

No menos me ha causado pesadumbre ver la desigualdad que tiene el mundo, entre la niebla de la vasta lumbre.

En Salomón este derecho fundo y pues el orbe no admitió remedio menos el hombre en término segundo [. . . ]

Veo la inequidad artificiosa sobre la cumbre de la humana vida abatir la justicia poderosa.

Veo que reina la soberbia asida al trono de Babel, lisonjeando la tiránica acción del homicida

Veo al pobre los bienes mendigando y al rico, siendo escándalo del cielo, sin virtud los tesoros aumentando.

Cáusame gran dolor, más desconsuelo, que un necio mande sin razón un sabio, fundando necesades en el duelo [. . .]

iAy de mil que nací desposeído del derecho sagrado, pues se ofrece

\footnotetext{
21 Otra interpretación posible, que propone mi estimada colega Constance Hubbard Rose de Boston, es que Enríquez Gómez buscaba una religión universalista, en la cual se reconciliaran el judaismo y el cristianismo; esto se ve en las alusiones a las leyes de Noé en La culpa, pp. 120-121. Si es así, puede haber sido influido por el jesuíta Antonio de Vieira; véase para esto $A$. J. SARAIVA, "Antonio Vieira, Menasseh ben Israel et le Cinquieme Empire", Studia Rosenthaliana, I (1972), 25-56. Debo agradecer a la profesora Constance $H$. Rose el haberme informado sobre este último artículo, así como su ayuda inapreciable en todo a cuanto se refiere a Antonio Enríquez Gómez.
} 
el rico a sepultarme con olvido.

Cuatro cosas mi ánima aborrece:

pobre soberbio, trono sin justicia, sexo sin honra y viejo que apetece.

Cinco abomino: falsedad, delicia, adúltero, homicida y poco menos un malsín sobornado de codicia.

(Culpa, fragmento 2, 1-6, 10-21, 25-33)

Aun sin la referencia directa a Salomón en el cuarto verso, que nos indica la fuente, es claro que el tono de este pasaje es el del Eclesiastés. Más aún, los primeros versos toman el tema frecuente de ese libro, la aparente desigualdad del mundo (cf. Eclesiastés 4.1, 8.14 , etc), y hay un eco del estribillo "bajo el sol" en "la vasta lumbre"; los versos subsiguientes señalan los pecados y las locuras de los hombres, como en la fuente. Así, aunque hay pocas citas directas en este pasaje ${ }^{22}$, hay un sentido casi de cita textual y de fuerte reminiscencia. Esto, a su vez, se apoya en imitaciones estilísticas, como la secuencia que empieza con las repeticiones de "veo"; allí el eco salomónico del primero de los tres tercetos aparece en los dos segundos con temas que forman parte de las preocupaciones personales del poeta, pero tratado en el estilo de la fuente (la referencia a Babel y sus relaciones con la tiranía, 11.13-15, y la referencia al malsín, 1.33). Los últimos tercetos de la cita, basados en la técnica de enlistado de esa otra fuente del libro de la Sabiduría, que es Proverbios 6.16, dan otro ejemplo (tres de las abominaciones mencionadas, el hombre soberbio, el homicida y el malsín, se derivan de Proverbios 6.17-19).

El uso intenso de fuentes bíblicas - que otros tantos pasajes demuestran ${ }^{23}$ - recuerda a Pinto Delgado, aunque el enfoque sea menos erudito y más literal o textual. Sin embargo, refleja una actitud que es notable en otros de sus escritos, es decir, una especie de reverencia por las Sagradas Escrituras que, en combinación con un rechazo evidente de la alegorización de la Biblia $^{24}$ y el hecho de que evita toda alusión trinitaria o cristológica ${ }^{25}$, equivale a una expresión de la identificación del poeta con el judaismo.

22 Una de las citas directas pertenece al Libro de Job: compárese 11.25-6 con Job 27:2 "Biue el Dios que me quitó mi derecho". La versión de la Biblia que se cita es la de Casiodoro de Reyna, Basilea, 1569, que usó Enríquez Gómez.

${ }^{23}$ Véase, por ejemplo, la secuencia final de La culpa, "La verdadera Philosophia Moral" (pp. 144 ss.), y también el pasaje al que me refiero en la nota siguiente.

${ }^{24}$ Compárese, por ejemplo, otra muestra de su literalismo bíblico, el "canto de amor" de Adán y Eva en La culpa, que está inspirado en el Cantar de los Cantares, sobre la traducción de fray Luis de León. En ésta, los interlocutores son el "Esposo" y la "Esposa" de la poesía a lo divino, y la "fuente sellada" del Cantar 4:12 es una alusión a la Virgen, pero Enríquez escoge una combinación de citas directas con imágenes amorosas según la tradición de Garcilaso y Herrera.

${ }^{25}$ Hasta donde yo sé, no hay tales alusiones en las obras de Enríquez Gómez, con excepción de Política angélica, donde su métodoconsiste precisamente en adoptar la posición 
La afirmación más completa y más abierta del sentimiento judaico del poeta es, como ya hemos dicho, el "Romance al divín mártir", escrito alrededor de 1648 y que circuló en manuscrito entre las comunidades judías de Amsterdam y Livorno ${ }^{26}$. La obra está inspirada en el martirio en Valladolid, en 1644, de Lope de Vega y Alarcón, un converso al judaismo de familia de cristianos viejos. Está dividida en dos partes: un argumento contra el cristianismo en boca del agonizante y una visión escatológica de la llegada del Mesías, llena de profecías enigmáticas, de alusiones contemporáneas y con una evocación de los llamados "dolores de parto" del Mesías y la llegada misma. Esta visión está basada en fuentes del Zohar y de la Cábala, así como, naturalmente, en la Biblia; también toma su tónica general de las Trovas de Bandarra que, como se recordará, desempeñaron un papel importante en el movimiento sebastianista que llevó a la independencia de Portugal ${ }^{27}$.

En la primera parte del poema, la polémica religiosa, Enríquez Gómez utiliza todo su ingenio y su experiencia de escritor satírico, como lo muestra este ataque al concepto de la Trinidad:

Decir Dios Ley para siempre

oístes desde los cielos, y no guardar su palabra era engañar a su pueblo

Pues, si en Dios no puede haber este insolente argumento, ¿por qué, bárbaro, lo sigues con errores manifiestos?

La unidad siendo distinta no es unidad en ebreo, y Ley divida en dos no tiene seguro asiento.

Quererme tú reducir a tres distintos sujetos, multiplicando deidades con sus festivos desvelos, es decirme que la Causa se iguala con los efectos, y lo propio es para mí

de un católico conforme para poder atacar mejor a la Inquisición. Es interesante notar que, a pesar de todo su literalismo, no usa el término híbrido "yehovah" incluso cuando se encuentra en su fuente, la Biblia de Casiodoro de Reyna -como si respondiera a la prohibición judaica de pronunciar el Tetragrammaton.

${ }^{26}$ Véase mi artículo citado en la nota 6 supra, que está basado en mi tesis doctoral, Two poems of Antonio Enríquez Gómez: "Romance al divín mártir, Judá Creyente" and "Sansón Nazareno", University of London, 1976.

${ }^{27}$ Hasta cierto punto el "Romance" puede ser considerado como una respuesta "judía" al mesianismo de inspiración cristiana de las Trovas. Enríquez Gómez debía conocer la obra por su actuación a favor de la causa portuguesa; más aún, el jefe de la misión portuguesa en Francia, el marqués de Niza, fue responsable de su primera impresión en Nantes en 1944. 
dividirla en tres que en ciento.

Ridiculamente osado, retóricamente necio te opones a quien te dice: "Yo, el primero, yo, el postrero".

La plegaria de Lope de Vega que introduce la profecía mesiánica tiene un tono de conmovedora sinceridad: en ella las convenciones del verso a matorio en el siglo XVII, con sus antítesis y sus caprichos (especialmente en lo que se refiere a la vida y la muerte) se combinan con ecos del Cantar de los Cantares y del libro vernáculo de oraciones $^{28}$.

Divino Señor, que asistes

en el Trono en el excelso

Tribunal que vio Isaías

de los serafines bellos;

Dios de Abraham, Dios de Isaac,

Dios de Jacob, Rey eterno,

cuyo Nombre incircunscrito

sólo consta de sí mesmo;

Causa de todas las causas, Criador de tierra y cielo, sin principio y sin fin, y un solo Dios verdadero;

esta vida que me distes

por sacrificio te ofrezco,

y un corazón abrasado

en las aras deste incendio:

como nos dice David,

es sacrificio perfecto ${ }^{29}$.

Que muero por tu Ley, dicen

mas no entienden el conceto, que, si muero por quien vivo, ya vivo de lo que muero.

Amante soy de tu Ley y de tal suerte la celo, que muero por adorarla: |mira, Señor, si la quiero! [...]

Por vieja la repudiaron, y el oro de sus cabellos

${ }^{28}$ Las primeras dos estrofas son un eco de la invocación al Dios de los Patriarcas y al Dios de la Creación de $A m i d a h$ en la liturgia judía (véase, por ejemplo, Orden de oraciones, ed. Efraim Bueno \& Jona Abravanel, Amsterdam, 1649, pp. 189-190), mientras que el tema de la vida y la muerte también puede reflejar la misma idea que se encuentra en el tercer párrafo de la oración. Para un análisis, véase mi tesis citada supra, nota 26, pp. 151-154.

29 La referencia es al Salmo 51.19, que el poeta cita con frecuencia en su libro, Luis dado de Dios, París, 1645 en versión propia, "Corazón contrito y humillado es perfecto sacrificio". 
más que los rayos del sol alumbran el universo!

Sus ojos son de paloma, azules pero no negros ${ }^{30}$, y de dos blancos mellizos tiene sus hermosos pechos ${ }^{31}$.

(11.319-44, 353-60)

Hay un paralelo a esta evidente expresión de fe judaica en el poema épico de Enríquez Gómez, Sansón Nazareno, y se encuentra en la plegaria final del héroe que pide la fuerza necesaria para cometer su acto final de autodestrucción o martirio. En términos generales, es más grandilocuente, como corresponde al estilo épico, pero tiene una fuerza retórica cuyo efecto emocional se deriva del sentido de la propia debilidad del poeta, y de su poca obediencia a los preceptos religiosos en el pasado:

Dios de mis padres - dice-, Autor eterno, de los tres mundos soberanos Atlante, incircunscrito, santo y abeterno,[. . .] Causa, sí de las causas invisible, perfecto Autor de todo lo criado, pequé, Señor, pequé yo me condeno, misericordia pide el Nazareno.

Restituye Señor, la prodigiosa fuerza de mis cabellos a su fuego; alienta con tu mano poderosa el valor que perdí quedando ciego; tócame con tu llama luminosa pues a la muerte con valor me entrego; dame aliento, Señor, para vengarme y tu exilio eficaz para salvarme.

Yo muero por la Ley que tú escribiste, por los preceptos santos que mandaste, por el pueblo sagrado que escogiste y por los mandamientos que ordenaste; yo muero por la patria que me diste y por la gloria con que el pueblo honraste; muero por Israel, y lo primero por tu inefable Nombre verdadero.

El estilo es el de muchos de los poemas penitenciales de la época, pero no es demasiado romántico sugerir que se puede leer como el momento en que el poeta reúne sus fuerzas cuando está a punto de

${ }^{30}$ Cf. Cantar de los cantares 4:1, "tus ojos de paloma entre tus copetes", dice la Biblia de Casiodoro Reyna.

" Cf: Cantar 4:5, "Tus dos tetas, como dos cabritos mellizos de gama, que son apacentados entre lyrios". 
enfrentarse a la dura prueba de su regreso a España y que esto es lo que le da una particular intesidad conmovedora.

Los dos poemas, Sansón Nazareno y el "Romance al divin mártir" representan de cierta manera el anhelo del poeta por un judaismo que nunca alcanzaria en su forma auténtica. Quizás aquí es donde se encuentra el significado último de la poesía de Enríquez Gómez: en esta existencia marginal, en la vida que nunca encontró la solución limpia de la experiencia judía de Amsterdam ${ }^{32}$, sino que luchó en los límites de la sociedad cristiana a la que nunca podría integrarse. No es de sorprender que la figura del peregrino, símbolo de la inseguridad del converso, aparezca con más frecuencia en la obra de este poeta que en la de los otros ${ }^{33}$. El dilema de su posición, dividida entre lo aconsejable del exilio y el anhelo de volver a España, se expresa en forma conmovedora en un poema de Academias morales de las Musas, que toma como punto de partida un verso de Gacilaso que otros habían glosado antes que él, pero nunca con esta finalidad ${ }^{34}$. Empieza así:

Cuando contemplo mi pasada gloria y me veo sin mí, duda mi estado si ha de morir conmigo mi memoria.

En vano se lastima mi cuidado, conociendo que amar un imposible contradice del cuerdo lo acertado.

¿Qué importa que mi pena sea terrible, si consiste mi bien en mi destierro, decreto justo para ser posible?

Despeñado caí de un alto cerro, pero puedo decir seguramente que no nació de mí tan grande yerro.

Lloro mi patria y della estoy ausente, desgracia del nacer lo habrá causado, pensión original del que no siente.

Si pudiera mi amor de lo pasado hacer de olvido un pacto a la memoria, quedara el corazón más aliviado.

Mas es esta enemiga tan notoria, que porque sabe que me da disgusto, muerte me da con mi pasada gloria.

\footnotetext{
32 La vida en Amsterdam no siempre era tan satisfactoria, como lo comprobaron a sus expensas Spinoza y Uriel da Costa.

33 Véase Constance Hubbard Rose, "Antonio Enríquez Gómez and the literature of exile", $R F, 85$ (1973); éste sigue siendo el mejor estudio, hasta la fecha del simbolismo del "peregrino" en la obra de Enríquez Gómez y de sus antecesores.

94 Véase Garcilaso, Soneto I, v. 1: "Cuando me paro a contemplar mi estado", también glosado por Lope de Vega, entre otros.
} 
Miguel de Barrios es, con mucho, el más barroco de nuestros tres poetas: escribe en la segunda mitad del siglo XVII, y parece haber absorbido todas las influencias del culteranismo y del conceptismo en su estilo y en sus temas. Sin embargo, combina estas influencias con temas y referencias al judaismo y a los detalles cotidianos de la práctica religiosa judaica. Es una mezcla extraordinaria, por no decir esquizofrénica, que sin duda refleja sus años de "doble vida" entre Bruselas y Amsterdam (y que quizás también explique sus posteriores excesos sabatinos y su enfermedad mental). Buena parte de su poesía es en realidad de naturaleza efímera, y se ocupa de la vida de la comunidad judía de Amsterdam - panegíricos, versos de circunstancia, poesía burlesca y otras cosas por el estilo, obras que son muy interesantes desde el punto de vista histórico y social pero que, en general, no son del más alto nivel. Sin embargo, algunas de esas poesías tienen cierto encanto, especialmente sus versos burlescos, como por ejemplo su autorretrato, Romance burlesco. Pintase el Poeta persuadido de una Dama:

Por obedecerte (Clori) de mi propio soy Timantes esperando ser tu Apeles, por que seas mi Campaspe.

Mi cabello es algo ruvio, pero en concerva admirable, y aun te parezco al Demonio con estos cabellos de Angel.

Quiero llevarte a mi frente, por no encontrar con el Jaspe, y por ver si tus tropiezos caer en tentacion te hazen.

Encontrandose mis cejas tienen tan fiero combate, que con doblarse las puntas se pasan de parte a parte.

Mi ojos de aguja son, con ellos he de picarme, por que no los puede ver aunque los tengo delante.

En su lugar, mis narizes hazen ruydo notable, tan campanudas que suelen hasta en Olanda sonarse [. . . ]

Es mi tez cassi amarilla, de un muerto parezco imagen, soy Don Quijote en los modos en los passos Rocinante ${ }^{35}$. 
El mismo tono se usa con buenos resultados en un contexto judío, en la "Alabanza jocosa a la Ley santísima en la fábrica de la sinagoga", que explota la metáfora tradicional de la Ley como una hermosa mujer y la relaciona con el lugar de la Ley en el ritual de la sinagoga. (También incluye referencias a los que han muerto por la Ley en manos de la Inquisición). He aquí las tres primeras cuartetas:

¡Gran casa tiene la Ley!

¡Oh, qué enamorados halla!

¿Quién duda que son ilustres,

pues entran en tan gran casa?

Hasta los jueces del pueblo

han dado en galantearla,

mostrándose muy celosos viendo que con todos anda.

Timbre y no mancha le es esto, pues por recóndita causa cuando más galanes tiene entonces es más honrada.

Sigue toda una serie de juegos de palabras muy efectivos, especialmente sobre el tema de las letras y la escritura, que aparece en todo el poema: la obligación tradicional de copiar la Torah se describe jocosamente como "zurrarle la badana" y la búsqueda de indicios sobre la venida del Mesías en el texto bíblico se menciona de la manera siguiente:

Es mujer de letras tales, que los que anhelan su patria andan en puntos con ella por ser gente de esperanza.

La poesía "seria" de Barrios va desde los textos que no se distinguen ni en tema ni en estilo de los de sus contemporáneos cristianos hasta aquellos que tratan temas judíos, pero siempre en un estilo eminentemente barroco. Recorre toda la gama del desengaño (con ayuda de la antítesis y del oxímoron) en «A la muerte de Raquel», donde el patriarca Jacob lamenta la muerte de su esposa que tantos trabajos le costó obtener:

¡Ay, dice, gozo incierto!, ¡Gloria vana! ;mentido gusto!, jestado nunca fijo! ¿Quien fía en tu verdor, vida inconstante?

Pues cuando más robusta y más lozana, 
un bien que me costó tiempo prolijo me lo quitó la muerte en un instante.

En forma semejante, la idea de que todos los opresores de Israel terminan mal está basada, en "A la segura confianza", en el hecho de que "Todo humano poder es sombra vana", idea típica de la poesía del desengaño. La conclusión del poema no estaría fuera de lugar en una obra de Quevedo:

Oh infinita de Dios soberanía pues sin haber seguridad humana, viva seguro aquel que en ti confía.

El tema logra su expresión más conmovedora en los “Sonetos dobles fúnebres", escritos a la muerte de su mujer, donde la intensa emoción personal rebasa todo sentido de ejercicio estilístico ${ }^{36}$.

También recuerda a Quevedo otro poema, la "Real consideración del hombre", en el que Barrios se ejercita glosando el mismo texto atribuido a Pedro de los Reyes que usó Quevedo: "Yo, ¿para qué nací? Para salvarme”. Barrios logra un resultado aceptable, pero no hace ningún intento por inyectar algún elemento judaico; en realidad su versión, como las cristianas, se queda en el terreno del sentimiento de estar sumergido en el pecado mundano. Por otra parte, bien podemos suponer que la elección del tema, y posiblemente la del tratamiento, reflejan ese mismo sentimiento de culpa de los marranos por el pasado que observamos en la poseía de Joáo Pinto Delgado. Es interesante comparar este poema con el "Acto séptimo de contrición", que forma parte de toda una serie de poemas específicamente relacionados con el festival judio de Yom Kippur, el Día del Perdón, y los días que le preceden, pero que también está imbuido de un sentido del pecado con tintes cristianos. La tesis del poema es que, aunque otras partes del cuerpo cometen pecados, sólo los ojos, con las lágrimas, pagan por ellos. Es justamente tema del debate teológico o moralístico de las discusiones literarias de las academias de Madrid, y también de la Academia de los Floridos de Amsterdam, de la cual Barrios era un miembro importante. Se puede ver el tono en este fragmento:

Descubriste aguas a la tierra, y que tienes memoria (David canta) de que es el hombre polvo, si se encierra

${ }^{36}$ Citado parcialmente en Marrano poets; para el texto completo, véase K. R. SCHOLBERG, La poesia religiosa de Miguel de Barrios, Ohio, 1963, pp. 246-248. Esta última obra es el más completo estudio de la poesía religiosa de Barrios y ha sido de inmenso valor para la preparación de mi antología y de este ensayo. 
en mar de llanto que al infierno espanta; ya con foso de llanto a infernal guerra, muro terreno en tu memoria santa, descubro que tu agrado he conseguido en ser polvo, de aguas defendido.

La alusión al Salmo 103, verso 14: "Acuérdase que somos polvo" y a las aguas de la historia de la Creación (Génesis 1), que da la imagen dominante de la primera mitad del poema, no altera radicalmente el tono penitencial de inspiración cristiana. Pero, por otra parte, sí sugiere un intento de evocar y de unirse al contexto esencialmente judaico de toda la colección de Días penitenciales, de la que forma parte.

También es evidente, en "Providencia particular de DIos sobre Israel", el hecho de que como ejercicio de deliberación tiene sus raíces más en el debate teológico cristiano que en las controversias rabínicas. el tema es si el mayor favor que Dios ha hecho a Israel es su piedad o su justicia en contra de sus opresores. Al mismo tiempo, es evidente su intento de lograr propósitos judaicos y de introducir en el argumento múltiples evidencias de erudición judaica, ya sea bíblica o talmúdica. A la vez que toma mucho del Éxodo para ejemplificar la misericordia de Dios al liberar a Israel y al castigar a los egipcios idólatras, hace referencias directas a la exégesis rabínica en el elaborado contraste entre Miguel, Ángel de la Misericordia, y Gabriel Ángel de la Justicia:

Enseña la rabínica doctrina
que Micael, de la piedad glorioso
ángel, delante del Señor camina
más que el de la justicia presuroso:
porque aquél con dos alas encamina
al pueblo, en claro día nebuloso
pilar; éste a Daniel vuela con una
de mar oscuro fúlgida columna.

(11.49-56)

El resto del poema lleva, entretejiendo argumento y contra-argumento, hacia la conclusión de que "a la justicia así supera / la clemencia" y de que "merced es más preclara / redimir que vengar al que no es fuerte, / porque lo uno da vida y lo otro muerte".

En el extremo más judaico del espectro de la poesía de Barrios, encontramos al poeta haciendo una paráfrasis de las palabras de la liturgia de Yom Kippur en lengua vernácula, como en el «Acto sexto de contrición». Ahí apenas si introduce algún cambio en su fuente: "Dios nuestro y Dios de nuestros padres puro, / nuestra oración delante de tí venga ..." Aun al final, donde su versión es más libre, sigue muy apegada a la liturgia: 


\begin{abstract}
¿Da, o Morador de célicas alturas la maná del perdón a tus criaturas! Tú lo encubierto y descubierto sabes, en tu mano del mundo están las llaves, todo lo abarcas sabio y poderoso: perdona al pueblo misericordioso, líbranos de pecados y prisiones, por pedirte contritos nos perdones ${ }^{37}$.
\end{abstract}

Estos versos, que tanto se acercan al tono de su fuente, son los más contenidos y directos de las obras de Barrios y, como tales, son algo atípicos.

En general, por más judaico que sea el tema, el estilo de Miguel de Barrios es elaborado, artístico, lleno de artificios y de juegos de palabras y conceptos: en suma, barroco. Si vemos el conjunto de su poesía, parecería que se dio a la tarea de poner al servicio de su judaismo todos los artificios de ese estilo, incluyendo sus excesos, ya fuera para fines evidentemente religiosos, ya sea simplemente para evocar el carácter y las facetas cotidianas de la práctica religiosa comunitaria judía. Podemos añadir a los ejemplos ya dados los del "Pregón harmónico", con sus juegos de palabras serios sobre el tema del arrepentimiento asociado con los días sagrados (el período de Año Nuevo y del Día del Perdón); el auto sacramental judío en alabanza de los mártires de la Inquisición, Contra la verdad no hay fuerza que, fuera del aspecto de la religión que ejemplifica, es totalmente calderoniano; y el Imperio de Dios en la harmonía del mundo, una elaboración poética sobre el tema del primer día de la Creación. Aunque esta última obra está repleta de alusiones rabínicas y referencias cabalísticas, e incluso contiene una exégesis del texto hebreo de Génesis 1.1 (sin mencionar su tópico bíblico), sin embargo toma elementos de toda la cultura renacentista española, incluyendo la filosofía griega y los escritos de los Padres de la Iglesia, y contiene algunos de los mejores ejemplos de argumentación conceptista que haya dado la pluma de Barrios. También tiene un ejemplo excelente, aunque algo aislado, de descripción lírica, de complejidad y belleza gongorinas:

Con los rayos del sol las gracias bellas, partes del año y de su carro alientos, las sabias horas entre las estrellas,

${ }^{37}$ Compárese con la fuente del libro de oraciones: “¿Qué diremos delante ti, morador de altura, y qué recontaremos delante ti, morador de los cielos? de cierto las encubiertas, y las descubiertas tú sabes. Tú sabes secretos del mundo, y ocultas encubrimientos de todo bivo. . . Sea voluntad delante ti. A. [Adonai] nuestro Dio, y Dio de nuestros padres que perdones a nos a todos nuestros pecados, y perdones a nos a todos nuestros delitos, y perdones, y quites todos nuestros rebellos" (Orden de Ros Asanah y Kypur, ed. Bueno y Abravanel, Amsterdam, 1652, p. 366). 
la harmonía de cielos y elementos, la gentil Hebe echando sus centellas, la jovial Venus que une pensamientos a Dios alaban, por el son facundo que juntas hacen el sarao del mundo.

Con voz fragante la encendida rosa, Arión de hojas en delfín de espinas sonora la ave en ramas generosa al dulce son de cuerdas cristalinas, cuanto puebla con vida presurosa golfos amenos, selvas neptuninas son de Dios ecos, por tan raros modos, que sin salir de sí, resuena en todos.

(11.101-112)

Con esta cita que hace eco a uno de los maestros de la poesía de los Siglos de Oro, podemos concluir esta revisión general de tres poetas marranos: tres poetas cuyas voces hablan de los diversos caminos que siguieron hacia el judaismo que sentían como suyo, con los acentos de la cultura literaria de la España cristiana, que también formaba parte de su herencia.

Timothy OELMAN

Inglaterra.

* Traducción del artículo: Flora Botton Burlá. 